\title{
Guest-editorial
}

\section{Special Issue: Selected papers from the KES2004 conference}

\author{
Robert J. Howlett ${ }^{\mathrm{a}}$ and Mircea Gh. Negoita ${ }^{\mathrm{b}}$ \\ ${ }^{\mathrm{a}}$ Intelligent Systems and Signal Processing Research Group, University of Brighton, UK \\ E-mail:r.j.howlett@brighton.ac.uk \\ ${ }^{\mathrm{b}}$ Centre for Computational Intelligence, Wellington Institute of Technology, New Zealand \\ E-mail: mircea.negoita@weltec.ac.nz
}

The Eighth International Conference on Knowledge Based Intelligent Information and Engineering Systems was held at the Intercontinental Hotel, Wellington, hosted by Wellington Institute of Technology, New Zealand in September 2004. KES2004 aimed to provide a high-tech forum for the presentation of recent research into the theory and applications of intelligent systems and techniques. However, it also focused on some significant emerging intelligent technologies including evolvable hardware, evolutionary computation in computational intelligence, DNA computing, artificial immune systems, bioinformatics using intelligent and machine learning techniques, and intelligent web mining. The conference attracted about 500 delegates from 55 countries and the proceedings contained approximately 500 papers.

This Special Issue contains extended versions of nine papers presented at KES2004, selected for qualities of innovation, application of leading-edge intelligent techniques, or overall excellent quality research.

The first paper, by A. Kusiak, A. Burns and F. Milster, describes a data-mining approach applied to the analysis of parameters relating to a circulating fluidisedbed boiler. The outcome of the research has interesting implications on the direction of research into the optimisation of energy production. The second paper, by B. Kostek and J. Wojcik, describes innovative work in which techniques often used in data-mining were applied to improve the effectiveness of the retrieval of stored musical rhythms. The next paper, by J.A. Rose, describes work relating to recent developments in DNA computing. Theory and results are presented. The fourth paper, by M.F. Ursu, B. Virginas, G. Owusu and
C. Voudouris, describes an approach to workforce allocation, modelled as a distributed system. The work combines an agent-based model combined with rulebased expressions in an original combination. Good global solutions are obtained from the distributed algorithm. The fifth paper, by V.K. Murthy, describes research in which contextual knowledge management in peer to peer computing is applied to mobile-multiplayer games and robotics. Paper number six, by M. Ong, X. Ren, G. Allan, V. Kadirkamanathan, H.A. Thompson and P.J. Fleming, presents a practical framework under which to build a decision support system using a Grid computing paradigm. The system is applied to aeroengine monitoring. The next paper, authored by $\mathrm{R}$. Ranawa, V. Palade and G.E.M.D.C. Bandara, describes an approach to the automatic generation of a fuzzy rule base for on-line hand-written alphanumeric character recognition. The method was found by the authors to be reliable and simple. The penultimate paper of the selection, written by D. Kim, N.-H. Kim, S.-J. Seo and G.-T. Park, describes simulation-based work that uses a fuzzy system to effectively model a practical walking bipedal robot. The final paper of the special issue, authored by V. Gorodetsky, O. Karsaev and V. Samoilov, describes an intelligent systems based generic approach to the on-line updating of situation assessment.

We would like to thank the authors for informing us of the results of their work through their papers. We would also like to thank the reviewers for their comments, which resulted in improvements in the papers.

We hope that readers appreciate from the papers some of the challenges of modern intelligent systems research, and some of the approaches that are being adopted to overcome them. 